\title{
Clinical Profile of Pediatric Burn Patients in Burn Care Unit of Halibet Hospital in 2018: Asmara, Eritrea
}

This article was published in the following Dove Press journal: Pediatric Health, Medicine and Therapeutics

\author{
Mahmud Mohammed (D)' \\ Yohannes Mekonen ${ }^{2}$ \\ Hermon Berhe ${ }^{3}$ \\ 'Department of Pediatrics and Child \\ Health, Orotta College of Medicine and \\ Health Sciences, Asmara, Eritrea; \\ ${ }^{2}$ Barentu Referral Hospital, Barentu, \\ Eritrea; ${ }^{3}$ Afabet Hospital, Afabet, Eritrea
}

Background: Pediatric burn injuries result in severe and long-term complications in the developing world, especially in sub-Saharan Africa. Accurate data on burn injuries are either unavailable or incomplete in Eritrea.

Objective: The objective of this study was to define the clinical characteristics of pediatric burn injuries in the Burn Care Unit of Halibet hospital in 2018 in Asmara, Eritrea.

Methods: The study design was a retrospective cross-sectional descriptive study. The medical records of pediatric patients aged 15 years and below admitted to the Burn Care Unit of Halibet hospital between January 2018 and December 2018 were assessed.

Results: In the study period, 524 children with burn injuries were admitted to the Unit. The mean age of the study group was $4.2 \pm 3.7$ years. Nearly $75 \%$ of the patients were in the age group 1-5 years. In $95.3 \%$ of the patients, scalds were the most common type of burn with burn injury occurring mostly indoor in $98.1 \%$ of cases. The average length of hospital stay was $4.6 \pm 8.4$ days with a median of 1 day. In $94.8 \%$ of the patients, the body surface area involved was $1-10 \%$, and the most body part involved was the extremity in $80.7 \%$ of the cases. Patients with body surface involvement $>10 \%$ and who came from rural areas stayed longer in hospital and those with scald burns have a shorter hospital stay. Patients with body surface area involvement $>10 \%$ and who came from rural areas also have more complications.

Conclusion: The most affected age group were $1-5$ years old children with scalds being the most common type of burns with injury occurring mostly indoors in this population. Teaching parents about household safety, seeking early medical attention, and raising public awareness could decrease the incidence of burn injury in children.

Keywords: childhood burn injury, pattern, outcome, Eritrea

\section{Introduction}

Greater than 300,000 people die every year from fire-related burn injuries. ${ }^{1}$ Children are exposed to various physical injuries because of their greater vulnerability: owing to their physical size, inability to recognize and evaluate hazardous situations, and skin sensitivity. ${ }^{2}$ One form of such injuries is burn. The broad definition of burn according to the World Health Organization (WHO) is "an injury caused by heat (flames, hot objects, or gases), chemicals, electricity and lightning, friction, or radiation". 3 In accident-related trauma deaths burn is the third top cause in all age groups and the second in children below the age of four years. ${ }^{4}$ This type of injury, together with other leading causes is particularly
Correspondence: Mahmud Mohammed Department of Pediatrics and Child Health, Orotta College of Medicine and Health Sciences, Asmara, Eritrea Tel +29l I 7144184

Email mahmudfil@yahoo.com
Pediatric Health, Medicine and Therapeutics 202I:|2 I3-2I 
problematic because of associated high death rates, limited treatment successes, and risks of life-long scars and disabilities. The immediate result of burn is increased by continuous pain, physical and cosmetic disfigurement, and the need for multiple dressing changes and surgical procedures. The constant emotional and psychological impact affects not only the injured child but also the parents and caregivers. ${ }^{5}$

According to one review study done in sub-Saharan Africa, burn injury is increasing due to the prevalent illiteracy, poverty, crowded towns, and movement of people to towns all over Africa. ${ }^{6}$ Although burn injury is equally prevalent in Africa in comparison to the Eastern Mediterranean and the South East Asian regions, incomplete data has been gathered regarding the epidemiology of burn injury in the African region. Many worldwide systematic reviews of burn injuries that include Africa have frequently recognized different risk factors and epidemiological patterns. ${ }^{5}$ Sex, age, seasonal and temporal variation, the potential for supervision (in pediatric burns), the extent of burn injury including total body surface area (TBSA) and burn depth, and other potential risk factors (eg, medical co-morbidities, flammable clothing, and cultural practices) are some of the important risk factors identified. $^{5}$

The burden of child burn-related deaths globally is 2.5 per 100,000 throughout 103 countries with the major burden in sub-Saharan Africa (4.5 per 100,000). ${ }^{7}$ If all countries in the world had similar rates as the top-performing group of high-income countries yearly, thirty-four thousand lives could be saved; the majority in low-income countries. ${ }^{7}$ Each year, burns result in above 7.1 million injuries, the loss of almost 18 million disability-adjusted life years (DALYs), and more than 250,000 deaths worldwide. ${ }^{5}$ It was shown that the majority of the burden of burn injury is endured by lowand middle-income countries. ${ }^{5}$ Survivors of burn develop wound contractures and other physical impairments that limit function and lessen their chance of living economically fruitful lives. ${ }^{1}$ In Ethiopia, pediatric admissions with burn injury accounted for $0.8 \%$ and $1.7 \%$ of all pediatric admissions, respectively, according to two retrospective analyses. ${ }^{8,9}$ In India, pediatric burns constitute a substantial proportion $(16.6 \%)$ of total burn admissions. ${ }^{10}$

Epidemiological data on burn injuries is not available in Eritrea. Albeit the exact magnitude of the problem has not been documented, anecdotal evidence from clinical practice shows that children are burned frequently throughout the country and under-reporting of cases remains a major issue.

Regarding burn injuries, despite their significant tolls of mortality, morbidity, and economic hindrances, little has been done to address the problem. To our knowledge, there have been no studies conducted to examine the clinical profile, risk factors, and outcome for a burn injury in the general or pediatric population in Eritrea. A detailed understanding of the clinical profile and outcomes are the crucial first steps to planning preventive measures.

Therefore, this study was designed to examine the clinical characteristics of pediatric burn injuries in the Burn Care Unit of Halibet hospital and the findings may help to design potential preventive measures.

\section{Materials and Methods}

\section{Study Design and Setting}

This was a retrospective descriptive cross-sectional study using a quantitative approach carried out in the Burn Care Unit of Halibet Hospital in Asmara, Eritrea. Halibet hospital is the second biggest hospital in Asmara, the capital city of Eritrea. It is a Zonal referral hospital for the central region as well as a national referral center for Burn Care, Orthopedic, and other specialized care units. It is the sole Burn Care Unit in the country that was established in April 2008 by the Ministry of Health of Eritrea and the German Hammer Forum Association. Halibet Burn Care Unit is a 17-bed facility with one operating room that can accommodate around 1300 burn patients of all age groups yearly from all over the country. Historical data documented between January 2018 and December 2018 were collected from February to April 2019.

\section{Data Sources}

Patients' registers and medical records were used as data sources to document historical data of pediatric patients, aged 15 years and below, admitted due to burn injury at the Burn Care Unit of Halibet national referral hospital to obtain demographic and clinical features.

The sample was the list of all pediatric inpatients for the year 2018. The sample population included pediatric patients with the following criteria:

\section{Inclusion and Exclusion Criteria}

Medical records of pediatric patients aged 15 years and below with a clinical diagnosis of burn injuries ("an injury caused by heat (flames, hot objects, or gases), chemicals, 
electricity and lightning, friction, or radiation" according to WHO definition) were included.

Medical records of patients discharged against medical advice, extensive missing data within the hospital card, treatment dropout, and loss of follow-up were excluded (Figure 1).

\section{Sample Size and Sampling Technique}

This study captured all eligible pediatric patients aged 15 years and below admitted between January and December 2018 in the Burn Care Unit of Halibet national referral hospital. Thus, the study was census and timebound and did not use any other sampling technique.

\section{Study Variables}

We included the following variables:

Dependent Variable: includes outcome (recovery without complications, burn with complications, and death) and duration of hospital stay in days.

Independent Variable: Demographic factors (age, sex, address, seasonal variation, place of burn) and clinical factors (etiology, depth of the burn, body surface area involved, and time of presentation after injury in hours).

\section{Data Collection}

Historical data was collected/abstracted from patients' medical records and registers using a checklist. The checklist includes patients' demographic characteristics, clinical features, clinical outcomes, and hospital stay. Data was collected by nurse practitioners working in the facility after a one-day orientation was given on the data collection procedures. The year 2018 is selected since it was the recent year with easier accessibility of medical records.

\section{Statistical Analysis}

Data were extracted using a checklist on the demographic and clinical profiles of participants' information. Data entry and analysis were performed using SPSS version 23 (SPSS Statistics for Windows, Version 23.0. Armonk, NY: IBM Corp). Variable with considerable deviation from the mean were binary grouped (age and duration of hospital stay). Descriptive statistics for categorical variables were presented as frequency and percent to describe the characteristics of the cases. The relationship between factors of interest with the duration of hospital stay (in days) and complications/death was explored by percent (\%) or $\chi^{2}$ tests (for categorical variables). Bivariate and multivariable logistic regression was used to evaluate the strength of the relationship between outcome variables (recovery without complications, burn with complications, and death), hospital stay with demographic variables. The odds ratio (OR) and $95 \%$ confidence interval $(95 \% \mathrm{CI})$ were calculated for each factor. Variables with a $10 \%$ change in the OR in the bivariate analysis were included in the model. Results were reported as OR and 95\% $\mathrm{CI}$ to assess the associations. P-values less than 0.05 were considered statistically significant.

\section{Ethical Considerations}

Approval for the study was given by the Research Ethics and Protocol Review Committee of the Eritrean Ministry of Health, the medical director of Halibet Hospital, and the Department of Statistics and Archives in Halibet Hospital. All the data collected from the records of respondents will be kept confidential at all times. Consent to participate was not obtained from the patients or guardians because the study was based on anonymized patient records. All

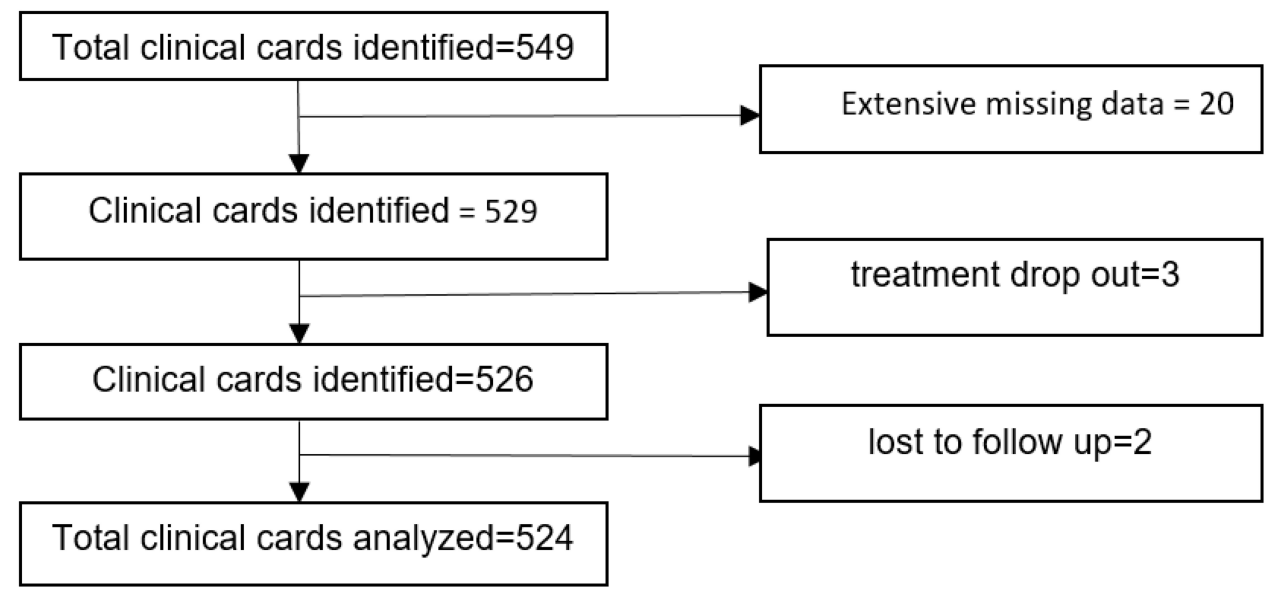

Figure I Flow chart of identified clinical cards. 
procedures of the study also followed the recommendation of the Declaration of Helsinki Convention.

\section{Results}

\section{Patient Characteristics}

During the study period, out of 1395 burn admissions of all age groups, 524 children with burn injuries were admitted to the Burn Care Unit. Pediatric burns constitute a considerable proportion (37.6\%) of total burn admissions. Almost all (94.8\%) of the burn patients in this study were self-referred. Of these, $51.7 \%$ were males with a male to female ratio of 1.1:1. Their ages ranged from 1 to 15 years with a mean of $4.2 \pm 3.7$ and a median of 3 years. Children aged $1-5$ years were the majority and accounted for $74.8 \%$. Children 4-15 years old have more complications (AOR=4.14, 95\% CI: $1.24-13.79, \mathrm{P}=0.021$ ) than those under the age of 4 years. Most of them were from urban $72.5 \%$, and $27.5 \%$ came from rural areas (Table 1). Patients who came from rural areas stayed longer $(\mathrm{OR}=2.92,95 \% \mathrm{CI}: 1.95-4.36, \mathrm{P}<0.001)$ in hospital compared to those who came from urban. This difference

Table I Demographic Characteristics of the Study Group

\begin{tabular}{|c|c|c|c|}
\hline Variables & Category & $\mathbf{N}$ & $\%$ \\
\hline \multirow{4}{*}{$\begin{array}{l}\text { Age group } \\
\text { (mean } 4.2 \pm 3.7, \text { median } 3)\end{array}$} & Total & 524 & $100 \%$ \\
\hline & $1-5$ & 392 & $74.8 \%$ \\
\hline & $6-10$ & 82 & $15.6 \%$ \\
\hline & $11-15$ & 50 & $9.5 \%$ \\
\hline \multirow[t]{2}{*}{ Gender } & Male & 271 & $51.7 \%$ \\
\hline & Female & 253 & $48.3 \%$ \\
\hline \multirow[t]{2}{*}{ Address/Residence } & Urban & 380 & $72.5 \%$ \\
\hline & Rural & 144 & $27.5 \%$ \\
\hline \multirow[t]{4}{*}{ Seasonal variation of admissions } & Summer & 145 & $27.7 \%$ \\
\hline & Autumn & 61 & $11.6 \%$ \\
\hline & Winter & 167 & $31.9 \%$ \\
\hline & Spring & $15 \mid$ & $28.8 \%$ \\
\hline \multirow[t]{2}{*}{ Place of injury } & Indoor & 514 & $98.1 \%$ \\
\hline & Outdoor & 10 & $1.9 \%$ \\
\hline \multirow[t]{3}{*}{ Cause of burn* } & Flame & 21 & $4.1 \%$ \\
\hline & Scald & 485 & $95.3 \%$ \\
\hline & Electrical & 3 & $0.6 \%$ \\
\hline
\end{tabular}

Note: *Some missing data. also remained significant after adjustment $(\mathrm{AOR}=2.88$, 95\% CI: $1.87-4.45, \mathrm{P}<0.001$ ) (Table 3). The outcome of burn with complications or death was more than four times higher $(\mathrm{OR}=4.69,95 \% \mathrm{CI}$ : $1.67-13.14, \mathrm{P}=0.003)$ before the adjustment and was more than three times higher ( $\mathrm{AOR}=3.42,95 \% \mathrm{CI}: 1.16-10.13, \mathrm{P}=0.026)$ after adjustment in those children who came from rural areas (Table 4). In this study, only 2 patients have epilepsy as a comorbid condition, and 11 patients have had traditional medicine before they arrive at the hospital.

\section{Settings of the Burn Injury}

The majority of the burn injury, $98.1 \%$, occurred indoor at home during the winter season, $31.9 \%$, mainly with scald type of burn $95.3 \%$ (Table 1). About half (51.3\%) of burn patients presented to the hospital after 24 hours, $27.3 \%$ of them presented within 6 hours, and $9.9 \%$ came within 6-24 hours after the burn injury. Those who came to the Burn Unit after 24 hours stayed shorter in the hospital in comparison to those who came early before 23 hours after the injury $(\mathrm{OR}=0.82,95 \% \mathrm{CI}: 0.56-1.20, \mathrm{P}=0.310)$. After adjustment, patients who arrived at the Burn Unit after 24 hours, stayed shorter than those who arrived early in less than 23 hours after the injury, and this difference was statistically significant $(\mathrm{AOR}=0.62,95 \% \mathrm{CI}: 0.41-0.95$, $\mathrm{P}=0.028$ ) (Table 3).

\section{Characteristics of the Burn Wound}

Twelve (2\%) of the patients presented late with contracture, and $95.25 \%$ of them had a second-degree burn. In $94.8 \%$ of them, the body surface area involved was $1-10 \%$ with the most body part involved was the extremity in $80.7 \%$ of the cases (Table 2). Patients who had body surface involvement $>10 \%$ stayed longer in hospital than those with $<10 \%$ body surface involvement, and the difference was statistically significant (OR=10.79, 95\% CI: 4.01-29.03, $\mathrm{P}=<0.001)$. This difference was consistently higher after adjustment (AOR=10.92, 95\% CI: 3.89-30.67P $=<0.001) \quad$ (Table 3). A significant increase in the rate of burn with complication or death was also observed in those with $>10 \%$ body surface area involvement $(\mathrm{AOR}=4.10,95 \% \mathrm{CI}: 1.12-15.19 \mathrm{P}=0.035)$ (Table 4). Patients with scald burn had a significantly shorter hospital stay rate than those who had other types of burn, and this difference was significant ( $\mathrm{AOR}=6.96,95 \%$ CI: 2.62-18.50, $\mathrm{P}=<0.001$ ) (Table 3). However, no difference in burn with complication or death was detected $(\mathrm{P}=0.152)$ (Table 4). The median duration of stay in the hospital was one day ranging between 1 and 66 days (Table 2). 
Table 2 Hospital Stays, Treatment, and Burn Outcomes

\begin{tabular}{|c|c|c|c|}
\hline Variables & Category & $\mathbf{N}$ & $\%$ \\
\hline \multirow{4}{*}{$\begin{array}{l}\text { Hospital stay in days } \\
\text { (median=I, IQR=4) }\end{array}$} & I day & 358 & 68.3 \\
\hline & $2-7$ days & 81 & 15.5 \\
\hline & $8-14$ days & 53 & 10.1 \\
\hline & More than 15 days & 32 & 6.1 \\
\hline \multirow[t]{3}{*}{ TBSA in percentage } & $1-10$ & 497 & 94.8 \\
\hline & $11-20$ & 20 & 3.8 \\
\hline & $21+$ & 7 & 1.3 \\
\hline \multirow[t]{9}{*}{ Treatment } & Closed dressing & 524 & 100.0 \\
\hline & Escharotomy & I & 0.2 \\
\hline & Graft & 36 & 6.9 \\
\hline & Debridement & 20 & 3.8 \\
\hline & Contracture Release & 12 & 2.3 \\
\hline & Other & 12 & 2.3 \\
\hline & IV resuscitation & 38 & 7.9 \\
\hline & Antibiotics & 41 & 8.5 \\
\hline & $\begin{array}{l}\text { Topical cream } \\
\text { (silver sulfadiazine) }\end{array}$ & 458 & 95.0 \\
\hline \multirow[t]{3}{*}{ Outcome } & $\begin{array}{l}\text { Discharged without } \\
\text { complication }\end{array}$ & 507 & 96.9 \\
\hline & Burn complication & 15 & 2.9 \\
\hline & Death & I & 0.2 \\
\hline \multirow[t]{3}{*}{ Complication* } & Infection & 5 & 33.3 \\
\hline & Contracture & 12 & 80.0 \\
\hline & Other & 2 & 13.3 \\
\hline
\end{tabular}

Note: *Patients reported more than one complication.

\section{Management Parameters}

All of the cases were managed with closed dressing and topical cream silver sulfadiazine was applied to most of them (95\%). Skin graft was done in $6.9 \%$ of the patients, debridement in $3.8 \%$, and $2.3 \%$ of the patients presented late to the unit with contracture, and contracture release was done. Forty-one $(8.5 \%)$ of the patients needed antibiotic treatment. The majority (96.9\%) of the patients were discharged without complications, one patient died and 15 had burn complications. From the burn complications, 5 (33\%) presented with superimposed infections, $12(80 \%)$ presented with contractures and $2(13.3 \%)$ developed surgical site infection and sepsis (Table 2).

\section{Discussion}

Investigating clinical profiles of burn injuries is vital for assessing the usefulness of existing treatment methods and for implementing effective prevention methods in the future, but they have not been done in Eritrea. Our study focused on the clinical profiles of pediatric burn inpatients at the Burn Care Unit in Eritrea in 2018.

In this study, the majority ( $74.8 \%$ ) of the subjects were $1-5$ years old. Our results are similar to a study done in Iran, ${ }^{11}$ where $58.7 \%$ of patients were below the age of 6 years, and Tanzania, where most patients were below the age of 5 years. ${ }^{12}$ Children in the age group $1-5$ years have increased occurrence of burns, this is because of their curiosity to investigate their environment as well as the lack of instinct to understand the danger of certain objects and most notably due to unregulated living environments in a developing country. ${ }^{12}$ Because of lack of adult supervision, an increase of newly-attained motor skills, and activity in these age groups they could encounter hot solids, hot liquids, electrical cords, and candles. ${ }^{13}$

Males were to some degree more affected than females in this study with a male to female ratio of $1.1: 1$ which is similar to a study done in Indonesia, Cameroon, and Pakistan. ${ }^{14-16}$ This may be due to males are assumed to be the more active sex, exposing themselves to activities that produce injuries and a pattern of more risk-taking and rougher play than females. However, studies done by other authors have found a predominance of female patients in comparison to male Patients. ${ }^{17}$

In our study scald was the leading cause of burn in $92.6 \%$ of the cases, similar results were observed in a Chinese study ${ }^{18}$ where $83 \%$ of $0-6$-year-olds sustained scald burn, and in another South African study which was $83 \%$ of the cases. ${ }^{19}$ Patients who had scald burn in our study had significantly shorter hospital stays in comparison with those who had other types of burn. Clinically it is expected that scald injury results in superficial burns that heal fast without surgical intervention and therefore early discharge from hospital compared to patients with other types of burns. However, scalds were the leading cause of pediatric burns followed by flames, independent of country and socioeconomic status. ${ }^{19}$

In this study, $98.7 \%$ of burn injuries occurred at home, which is similar to other studies done elsewhere. ${ }^{19}$ In developing countries home is a risky place for children as there is no enough space for children to play so that they could easily come in contact with hot fluids and solids with 
Table 3 Bivariate and Multivariable Logistic Regression Analysis of Length of Hospital Stay in Days

\begin{tabular}{|c|c|c|c|c|c|c|c|c|}
\hline \multirow[t]{2}{*}{ Predictor Variables } & \multicolumn{2}{|c|}{ Hospital Stay in Days } & \multicolumn{3}{|c|}{ Bivariate Analysis } & \multicolumn{3}{|c|}{ Multivariable Analysis } \\
\hline & I Day (\%) & >I Day (\%) & OR & $95 \%$ C.I & P-value & AOR & 95\% C.I. & P-value \\
\hline \multicolumn{9}{|l|}{ Age (in years) } \\
\hline $0-3$ & $223(69.9)$ & $96(30.10)$ & 1.00 & & & 1.00 & & \\
\hline $4-15$ & 135 (65.9) & $70(34.1)$ & 1.2 & $0.83-1.75$ & 0.331 & 1.02 & $0.67-1.55$ & 0.929 \\
\hline \multicolumn{9}{|l|}{ Sex } \\
\hline Males & $184(67.9)$ & $87(32.1)$ & 1.00 & & & & & \\
\hline Females & $174(68.8)$ & $79(31.2)$ & 0.96 & $0.66-1.39$ & 0.829 & $\psi$ & $\psi$ & $\psi$ \\
\hline \multicolumn{9}{|l|}{ Type of burn } \\
\hline Scald & $340(70.1)$ & 145 (29.9) & 1.00 & & & 1.00 & & \\
\hline Others & $6(25.0)$ & $18(75.0)$ & 7.03 & $2.74-18.09$ & $<0.001$ & 6.96 & $2.62-18.50$ & $<0.001$ \\
\hline \multicolumn{9}{|l|}{ TBSA (\%) } \\
\hline$<10 \%$ & $355(7 I)$ & $144(29)$ & 1.00 & & & 1.00 & & \\
\hline$>10 \%$ & $5(18.5)$ & $22(81.5)$ & 10.79 & $4.01-29.03$ & $<0.001$ & 10.92 & $3.89-30.67$ & $<0.001$ \\
\hline \multicolumn{9}{|c|}{ Duration of burn to presentation } \\
\hline$\leq 23$ hours & $128(65.6)$ & $67(34.4)$ & 1.00 & & & 1.00 & & \\
\hline$\geq 24$ hours & $230(69.9)$ & $99(30.1)$ & 0.82 & $0.56-1.20$ & 0.028 & 0.62 & $0.4 I-0.95$ & 0.028 \\
\hline \multicolumn{9}{|l|}{ Address } \\
\hline Urban & $285(75)$ & $95(25.0)$ & 1.00 & & & 1.00 & & \\
\hline Rural & $73(50.7)$ & $71(49.3)$ & 2.92 & $1.95-4.36$ & $<0.001$ & 2.88 & I.87-4.45 & $<0.001$ \\
\hline
\end{tabular}

Abbreviations: TBSA, total body surface area; OR, odds ratio; AOR, adjusted odds ratio; C.I., confidence interval; $\psi$, not included in the final model.

uncovered containers in the single room. Similar to other studies our findings advocate that burn prevention approaches should emphasize on indoor burns, as that was the site where most burns were sustained in this age group. ${ }^{6}$

Burns of less than $20 \%$ TBSA represent the large majority of burns in previous studies as was also confirmed by our study. ${ }^{20,21}$ In this study, $94.8 \%$ of the cases have $0-10 \%$ TBSA involvement and $3.8 \%$ with $11-20$ TBSA involvement. In the present study burn patients with $>10 \%$ body surface area involved spent longer duration of hospital stay and have more complications compared to their counterparts $(<10 \%)$. This is in line with the previous study in Tanzania. ${ }^{22}$ The outcome of burn injury, length of hospital stay or complication, is influenced by the extent of burn (TBSA) as shown in our study.

There is seasonal variation in burn injuries in subSaharan Africa. During the cold dry winter season between October and February, an increased occurrence of burns is observed, ${ }^{23}$ similar to our findings which occurred in $31.9 \%$ of the cases. However, the difference in seasonal variation of burn incidence was not statistically significant in this study.

More than half $(57.9 \%)$ of burn patients presented to the burn unit late after 24 hours, of whom 5.2\% developed burn complications. Although late hospital presentation following burn injury increases the probability of longer hospital stay and complications as the child may be brought to the hospital after the wound became infected or referred from other remote health facilities; however, in this study, patients who presented late to this Burn unit stayed shorter than those who came early in 23 hours following the incidence. This could be because these injuries were minor so that the victims did not seek medical attention early. As this Burn Care Unit is the only one in the country transportation may affect patients coming from distant places and is a reason for delayed health-seeking, similar to other study. ${ }^{20}$ 
Table 4 Bivariate and Multivariable Logistic Regression Analysis for Discharge with Complication/Death

\begin{tabular}{|c|c|c|c|c|c|c|c|c|}
\hline \multirow{2}{*}{$\begin{array}{l}\text { Predictor } \\
\text { Variables }\end{array}$} & \multicolumn{2}{|l|}{ Discharge Outcomes } & \multicolumn{3}{|c|}{ Bivariate Analysis } & \multicolumn{3}{|c|}{ Multivariable Analysis } \\
\hline & $\begin{array}{l}\text { Without Complication } \\
\text { (\%) }\end{array}$ & $\begin{array}{l}\text { With Complication } \\
\text { (\%) }\end{array}$ & OR & 95\% C.I. & P-value & AOR & 95\% C.I. & P-value \\
\hline \multicolumn{9}{|c|}{ Age (years) } \\
\hline $0-3$ & $315(98.7)$ & $4(1.3)$ & 1.00 & & & 1.00 & & \\
\hline $4-15$ & $192(94.1)$ & $12(5.9)$ & 4.92 & $1.57-15.48$ & 0.006 & 4.14 & $1.24-13.79$ & 0.021 \\
\hline \multicolumn{9}{|l|}{ Sex } \\
\hline Males & $262(96.7)$ & $9(3.3)$ & 1.00 & & & 1.00 & & \\
\hline Females & $245(97.2)$ & $7(2.8)$ & 0.83 & $0.3 \mathrm{I}-2.27$ & 0.72 & 0.67 & $0.23-1.94$ & 0.47 \\
\hline \multicolumn{9}{|c|}{ Type of burn } \\
\hline Scald & 47I (97.3) & $13(2.7)$ & 1.00 & & & 1.00 & & \\
\hline Others & $21(87.5)$ & $3(12.5)$ & 5.18 & $1.37-19.56$ & $0.035^{*}$ & 2.92 & $0.67-12.67$ & 0.152 \\
\hline \multicolumn{9}{|l|}{ TBSA (\%) } \\
\hline$<10 \%$ & $484(97.6)$ & $12(2.4)$ & 1.00 & & & 1.00 & & \\
\hline$>10 \%$ & $23(85.2)$ & $4(14.8)$ & 7.01 & $2.0 \mathrm{I}-23.44$ & $0.007^{*}$ & 4.10 & $1.12-15.19$ & 0.035 \\
\hline \multicolumn{9}{|l|}{ Address } \\
\hline Urban & $374(98.4)$ & $6(1.6)$ & 1.00 & & & 1.00 & & \\
\hline Rural & $133(93.0)$ & $10(7.0)$ & 4.69 & $1.67-13.14$ & $0.003^{*}$ & 3.42 & $1.16-10.13$ & 0.026 \\
\hline
\end{tabular}

Notes: One case with missing information outcome was not included in the analysis. *Fisher's Exact Test was used.

Abbreviations: TBSA, total body surface area; OR, odds ratio; AOR, adjusted odds ratio; C.I., confidence interval.

Place of residence has a detrimental effect on early health-seeking behavior as well as good burn management outcomes. In this study, those who came from rural areas of residence stayed longer in the hospital than those who came from urban areas, and the difference was statistically significant $(\mathrm{p}<0.001)$. Lack of transportation could be one of the potential factors for delayed seeking medical attention and resulted in wound infection and deep wounds. This increases the probability of prolonged hospital stay, burn complications, or death consistent with a study done in Tanzania. ${ }^{22}$

\section{Limitations}

The main limitation of the study is its retrospective nature and the basic data are quite skewed towards scald injury, younger age group, $<10 \%$ body surface area involvement, and urban area of residence which leads to the limited statistical power of the associative explorations limiting to do strong conclusions. It is also a report of only one year which influences the statistical power and from one center which may not be representative of the whole country. We were not able to get also the nutritional status of the injured children from the patient cards to calculate body mass index as that may influence the outcome of burn injury.

\section{Conclusions}

The most affected age group was 1-5 years old children with scalds being the most common type of burns with injury occurring mostly indoors in this population. Because burn injuries are largely preventable, educating parents on household safety, seeking early medical attention, and raising the awareness of the public through media could decrease the incidence of the injury.

\section{Recommendations}

We recommend the following prevention strategies:

Educating parents on how to prevent burn injuries in young children through media. 
Opening burn care facilities in district hospitals to decrease delays with training nurses and doctors and introducing simple protocols of burn care.

We also recommend further extensive prospective studies on pediatric burn injuries to be conducted to map the problem and propose effective preventive strategies.

\section{Data Sharing Statement}

Data used for this study are all available in the manuscript. Where required, the full dataset can be found from the corresponding author upon request.

\section{Acknowledgments}

Our sincere appreciation goes to Ms. Luwam and Mr. Fasil, who helped in collecting data, Mr. Medhanie Asrat who helped during data entry, cleaning, and analysis, and Dr. Luwam Gebrehiwot, Dr. Kebede Beyene, and Amanuel Kidane for critical review of the manuscript, data analysis, and feedback.

\section{Author Contributions}

All authors made substantial contributions to conception and design, acquisition of data, or analysis and interpretation of data; took part in drafting the article or revising it critically for important intellectual content; agreed to submit to the current journal; gave final approval of the version to be published; and agree to be accountable for all aspects of the work.

\section{Funding}

The authors did not get any funds for this study.

\section{Disclosure}

The authors declare that they have no conflicts of interest for this work.

\section{References}

1. Peck M, Molnar J, Swart D. A global plan for burn prevention and care. Bull World Health Organ. 2009;87:802-803. doi:10.2471/ BLT.08.059733

2. Branche C, Ozanne-Smith J, Oyebite K, Hyder AA. World Report on Child Injury Prevention. World Health Organization; 2008.

3. Organization WH. International classification of diseases (ICD); 2010. Available from: http://apps.who.int/classifications/apps/icd/icd10on line. Accessed October 6, 2010.

4. Fernandes FMFDA, Torquato IMB, de Araújo Dantas MSDA, Júnior FDAC, de Araújo Ferreira J, Collet N. Queimaduras em crianças e adolescentes: caracterização clínica e epidemiológica. Revista Gaúcha De Enfermagem. 2012;33(4):133-141. doi:10.1590/ S1983-14472012000400017
5. Rybarczyk MM, Schafer JM, Elm CM, et al. A systematic review of burn injuries in low-and middle-income countries: epidemiology in the WHO-defined African Region. African $j$ Emergency Medicine. 2017;7(1):30-37. doi:10.1016/j.afjem.2017.01.006

6. Albertyn R, Bickler S, Rode H. Paediatric burn injuries in sub Saharan Africa-an overview. Burns. 2006;32(5):605-612. doi:10. 1016/j.burns.2005.12.004

7. Sengoelge M, El-Khatib Z, Laflamme L. The global burden of child burn injuries in light of country-level economic development and income inequality. Preventive Medicine Reports. 2017;6:115-120. doi:10.1016/j.pmedr.2017.02.024

8. Daniel E, Yoo M. Survey of burn admissions to the Ethio-Swedish Children's Hospital. Ethiop Med J. 1990;28(4):163-168.

9. Gedlu E. Accidental injuries among children in north-west Ethiopia. East Afr Med J. 1994;71(12):807-810.

10. Mehta MA, Bhatia VY, Sharma BP. A study of burns in the pediatric age group. Indian J Burns. 2013;21(1):55. doi:10.4103/0971653X.121884

11. Vahdati SS, Karzar BH, Momen N. Independent predictive factors of hospitalization in a North-West Burn Center of Iran; an Epidemiologic Study. Emergency. 2015;3(1):40.

12. Outwater AH, Ismail $\mathrm{H}$, Mgalilwa L, Temu MJ, Mbembati NA. Burns in Tanzania: morbidity and mortality, causes and risk factors: a review. Int J Burns Trauma. 2013;3(1):18.

13. Ho W-S, Ying S. An epidemiological study of 1063 hospitalized burn patients in a tertiary burns center in Hong Kong. Burns. 2001;27 (2):119-123. doi:10.1016/S0305-4179(00)00095-4

14. Wardhana A, Basuki A, Prameswara ADH, Rizkita DN, Andarie AA, Canintika AF. The epidemiology of burns in Indonesia's national referral burn center from 2013 to 2015. Burns Open. 2017;1 (2):67-73. doi:10.1016/j.burnso.2017.08.002

15. Fomukong NH, Mefire AC, Beyiha G, et al. Predictors of mortality of pediatric burn injury in the Douala General Hospital, Cameroon. Pan Afr Med J. 2019;33.

16. Iqbal T, Saaiq M. The burnt child: an epidemiological profile and outcome. J Coll Physicians Surg Pakistan. 2011;21(11):691-694.

17. Tadele A. Magnitude, Clinical Presentation, and Outcome of Pediatric Burn Injuries at Yekatit 12 Hospital, Addis Ababa. Ethiopia: Addis Ababa University; 2014.

18. Li H, Yao Z, Tan J, et al. Epidemiology and outcome analysis of 6325 burn patients: a five-year retrospective study in a major burn center in Southwest China. Sci Rep. 2017;7:46066. doi:10.1038/ srep46066

19. Parbhoo A, Louw QA, Grimmer-Somers K. A profile of hospital-admitted paediatric burns patients in South Africa. BMC Res Notes. 2010;3(1):165. doi:10.1186/1756-0500-3-165

20. Cheng W, Yan-Hua R, Fang-Gang N, Wei-Li D, Guo-An Z. Epidemiology of 1974 burn patients at a major burn center in Beijing: a nine-year study. J Burn Care Res. 2012;33(5):e228-e233. doi:10.1097/BCR.0b013e3182479b13

21. Tang K, Jian L, Qin Z, Zhenjiang L, Gomez M, Beveridge M. Characteristics of burn patients at a major burn center in Shanghai. Burns. 2006;32(8):1037-1043. doi:10.1016/j.burns. 2006.03.021

22. Chalya PL, Mabula JB, Dass RM, et al. Pattern of childhood burn injuries and their management outcome at Bugando Medical Centre in Northwestern Tanzania. BMC Res Notes. 2011;4(1):485. doi:10.1186/1756-0500-4-485

23. Kalyai G. Burn injuries in Zaria: a one-year retrospective study. East Afr Med J. 1997;71(5):317-321. 


\section{Publish your work in this journal}

Pediatric Health, Medicine and Therapeutics is an international, peerreviewed, open access journal publishing original research, reports, editorials, reviews and commentaries. All aspects of health maintenance, preventative measures and disease treatment interventions are addressed within the journal. Practitioners from all disciplines are invited to submit their work as well as healthcare researchers and patient support groups. The manuscript management system is completely online and includes a very quick and fair peer-review system. Visit http://www.dovepress.com/testimonials.php to read real quotes from published authors. 